\title{
PENGARUH BAURAN PEMASARAN TERHADAP KEPUTUSAN MENJADI NASABAH PT. BANK NEGARA INDONESIA (PERSERO) TBK KANTOR CABANG PEMBANTU MARTAPURA
}

\author{
${ }^{1}$ Rozi Sonjaya, ${ }^{2}$ Luis Marnisah, ${ }^{3}$ Fakhry Zamzam \\ ${ }^{1}$ Mahasiswa Program Magister Universitas IGM, Email:rozisonjaya@gmail.com \\ ${ }^{2}$ Program Magister Universitas IGM, Email: luismarnisah@uigm.ac.id \\ ${ }^{3}$ Program Magister Universitas IGM, Email: fakhry@uigm.ac.id
}

\begin{abstract}
This research aims to obtain the results of an analysis of the influence of the marketing mix on the decision to become a customer of PT. Bank Negara Indonesia (Persero) Tbk Martapura Sub-Branch Offices partially and simultaneously. The research methods using quantitative and qualitative approaches, field data collection using questionnaire and interview techniques. The population in this study was 138 customers who opened a savings account at BNI KCP Martapura in April 2020 and samples were 138 respondents. Testing the data using the t test, that the product has no significant effect on the decision to become a customer with $t$ count $1.901<t$ table 1.978, price does not significantly influence the decision to become a customer with $t$ count $-0.507<t$ table 1.978 , promotion does not significantly influence the decision to become a customer with $t$ count $1.826<t$ table 1.978, place has a significant effect on the decision to become a customer with t count $3.790>t$ table 1.978, people / bank officer have a significant effect on the decision to become a customer with $t$ count $2.771>t$ table 1.978, physical evidence do not have a significant effect on the decision to become a customer with $t$ count $1.276<t$ table 1.978 and the process has no significant effect on the decision to become a customer with $t$ count $1.650<t$ table 1.978. The F Test Results that the product, price, promotion, place, people / bank officer, physical evidence and process simultaneously have a significant effect on the decision to become a customer with an $F$ count of $35.055>F$ table 2.08. The results showed that the marketing mix variable that had the most significant effect on the decision to become a customer was the place variable. Strategies to increase the interest of prospective customers can be done by maintaining and improving strategic locations that are already owned and improving the skills and abilities of service personnel.
\end{abstract}

Keywords: Marketing Mix, Decision To Become A Customer.

\begin{abstract}
Abstrak
Penelitian ini bertujuan untuk mendapatkan hasil analisis pengaruh bauran pemasaran terhadap keputusan menjadi nasabah PT. Bank Negara Indonesia (persero) Tbk Kantor Cabang Pembantu Martapura secara parsial dan simultan. Metode penelitian menggunakan pendekatan kuantitatif dan kualitatif, pengumpulan data lapangan menggunakan teknik kuesioner dan wawancara. Populasi dalam penelitian ini berjumlah 138 nasabah yang membuka rekening simpanan di BNI KCP Martapura pada bulan April 2020 dan sampel yang diambil sebanyak 138 responden. Pengujian data menggunakan uji t, bahwa produk tidak berpengaruh signifikan terhadap keputusan menjadi nasabah dengan $t$ hitung $1,901<t$ tabel 1,978, harga tidak berpengaruh signifikan terhadap keputusan menjadi nasabah dengan $t$
\end{abstract}


118 | Rozi Sonjaya, Luis Marnisah, Fakhry Zamzam, Pengaruh Bauran Pemasaran....

hitung $-0,507<t$ tabel 1,978, promosi tidak berpengaruh signifikan terhadap keputusan menjadi nasabah dengan t hitung 1,826 < t tabel 1,978, lokasi berpengaruh signifikan terhadap keputusan menjadi nasabah dengan thitung 3,790 > t tabel 1,978, Orang / Petugas Bank berpengaruh signifikan terhadap keputusan menjadi nasabah dengan thitung 2,771 > t tabel 1,978, Sarana Fisik tidak berpengaruh signifikan terhadap keputusan menjadi nasabah dengan $t$ hitung 1,276 < $t$ tabel 1,978 dan proses tidak berpengaruh signifikan terhadap keputusan menjadi nasabah dengan $t$ hitung 1,650 < t tabel 1,978. Hasil Uji F bahwa produk, harga, promosi, lokasi, orang / petugas bank, sarana fisik dan proses secara simultan berpengaruh signifikan terhadap keputusan menjadi nasabah dengan F hitung 35,055 > F tabel 2,08. Hasil penelitian menunjukkan bahwa variabel bauran pemasaran yang paling berpengaruh signifikan terhadap keputusan menjadi nasabah adalah variabel lokasi. Strategi untuk meningkatkan minat calon nasabah dapat dilakukan dengan mempertahankan dan memperbaiki lokasi strategis yang telah dimiliki serta meningkatkan skill dan kemampuan petugas layanan

Kata Kunci: Bauran Pemasaran, Keputusan Menjadi Nasabah.Kerja.

\section{DASAR PEMIKIRAN}

\section{Latar Belakang.}

Persaingan bisnis di dunia perbankan saat ini semakin kompetitif, hal ini disebabkan dengan banyaknya jumlah bank yang ada di Indonesia. Berdasarkan data Badan Pusat Statistik, per 31 Desember 2017 terdapat 115 bank yang beroperasi di Indonesia dengan jumlah kantor yang tersebar di seluruh wilayah Indonesia sebanyak 32.285 kantor (https://www.bps.go.id). Data tersebut menunjukkan bahwa kondisi persaingan bisnis yang ketat bagi bank-bank di Indonesia dalam menjalankan bisnisnya.

Untuk unggul dalam menghadapi persaingan, sebuah bank harus mampu menjaga dan mempertahankan nasabah yang sudah ada (Existing Customers), selain itu sebuah bank juga harus mampu mencari dan menambah nasabah baru untuk meningkatkan kinerja bank tersebut. Menjaga dan mempertahankan existing customers dapat dilakukan dengan beberapa hal seperti memberikan perhatian dan pelayanan yang baik kepada nasabah tersebut, menangani dan menyelesaikan komplain dari nasabah secara maksimal, sebuah bank juga harus mampu menciptakan produk-produk baru yang sesuai dengan kebutuhan dan yang diharapkan oleh nasabah. Ketatnya persaingan dalam mencari dan menambah nasabah baru, sehingga sebuah bank harus memiliki strategi pemasaran yang baik.

Beberapa strategi pemasaran yang biasa dilakukan oleh perusahaan termasuk perbankan adalah sebagai berikut: 
1. Menciptakan produk-produk yang unggul, yaitu produk yang sesuai dengan kebutuhan masyarakat.

2. Memberikan harga yang bersaing, untuk perusahaan perbankan dapat berupa biaya administrasi yang murah.

3. Melakukan promosi atas produk dan jasa yang ditawarkan.

4. Membuka usaha di lokasi yang strategis dan mudah dijangkau oleh masyarakat.

5. Menyediakan pegawai atau petugas yang handal untuk melayani konsumen.

6. Membangun atau membuat sarana fisik gedung kantor dan sarana fisik lainnya yang nyaman.

7. Memberikan proses yang cepat bagi konsumen untuk memiliki produk yang ditawarkan.

Ketujuh strategi diatas didalam dunia pemasaran dikenal dengan istilah Bauran Pemasaran atau Marketing Mix. Konsep Bauran Pemasaran pertama kalinya digunakan oleh Neil Borden pada tahun 1964 dengan konsep 4P yaitu Product, Place, Promotion dan Place. Selanjutnya pada tahun 1981 dikembangkan Konsep Bauran Pemasaran Jasa oleh Booms dan Bitner dengan menambah 3 (tiga) elemen untuk pemasaran jasa menjadi 7P yaitu Product, Place Promotion, Place, Participants/People, Physical Evidence dan Process (Booms, 1981).

Konsep Bauran Pemasaran telah diterapkan dibanyak perusahaan, baik perusahaan manufaktur maupun perusahaan jasa, begitu pula pada perusahaan perbankan seperti BNI, Mandiri, BRI, BCA dan Bank lainnya. Ketujuh konsep Bauran Pemasaran tersebut tentu menjadi hal yang penting untuk diterapkan secara konsisten.

PT. Bank Negara Indonesia (persero) Tbk adalah salah satu Bank BUMN yang mayoritas sahamnya dimiliki oleh Pemerintah Indonesia. Berdirinya Bank Negara Indonesia diresmikan pada Tanggal 5 Juli 1946 di Yogyakarta oleh Wakil Presiden Drs. Moh. Hatta. Bank Negara Indonesia (BNI) merupakan salah satu bank umum (komersial) yang meyelenggarakan perkreditan, menerima simpanan baik berupa giro, deposito, dan tabungan, menyelenggarakan jasa-jasa perbankan lainnya, serta memperdagangkan surat-surat berharga dan juga melakukan penanaman saham dalam modal perusahaan lain. Pada Tahun 1992 status perusahaan secara hukum menjadi PT 


\section{0 | Rozi Sonjaya, Luis Marnisah, Fakhry Zamzam, Pengaruh Bauran Pemasaran....}

Bank Negara Indonesia (Persero), yang kemudian menjadi perusahaan publik dengan melakukan penawaran saham perdana di pasar modal pada Tahun 1996.

Visi BNI adalah menjadi Lembaga Keuangan yang unggul dalam layanan dan kinerja. Adapun Misi BNI yaitu memberikan layanan prima dan solusi bernilai tambah kepada seluruh nasabah dan selaku mitra pilihan utama, meningkatkan nilai investasi yang unggul bagi investor, menciptakan kondisi terbaik bagi karyawan sebagai tempat kebanggaan untuk berkarya dan berprestasi, meningkatkan kepedulian dan tanggung jawab kepada lingkungan dan komunitas, serta menjadi acuan pelaksanaan kepatuhan dan tata kelola perusahaan yang baik (https://www.bni.co.id).

BNI Kantor Cabang Pembantu (KCP) Martapura merupakan salah satu outlet BNI yang berada dibawah supervisi BNI Kantor Cabang Baturaja. BNI KCP Martapura berlokasi di Kota Martapura Kabupaten OKU Timur Provinsi Sumatera Selatan yang dibuka sejak Tahun 2013, pada posisi 31 Januari 2020 BNI KCP Martapura mengelola sebanyak 8.991 rekening nasabah dana (Executive Information System BNI, 2020).

Area operasional BNI KCP Martapura meliputi Kabupaten OKU Timur di Provinsi Sumatera Selatan, di Kabupaten OKU Timur terdapat delapan bank yang beroperasi antara lain : BNI, BNI Syariah, BRI, Bank Mandiri, BPD Sumsel Babel, Bank Syariah Mandiri, BTPN, dan BPR Utomo. Masyarakat yang dilayani di BNI KCP Martapura, mayoritas sebagai pedagang, pengusaha, petani, dan pegawai (PNS/BUMN/Swasta).

BNI KCP Martapura memiliki satu unit pelayanan uang tunai, satu unit pelayanan nasabah (customer service) dan satu unit pemasaran. Sebagai salah satu outlet BNI, tentunya BNI KCP Martapura selalu berusaha menerapkan standar pelayanan yang sudah ditetapkan perusahaan dalam melayani nasabah dan selalu berusaha melakukan berbagai strategi pemasaran untuk menarik minat masyarakat menabung, bertransaksi dan menggunakan produk BNI. Salah satu strategi pemasaran yang dilakukan di BNI yaitu dengan menerapkan Konsep Bauran Pemasaran, namun dilapangan penerapan konsep Bauran Pemasaran tersebut sering mengalami kendala sehingga tidak memberikan hasil yang efektif, seperti kurangnya dukungan dari petugas layanan BNI sendiri, kurangnya tenaga layanan dan pemasaran untuk kantor BNI yang berada di daerah, promosi yang dilakukan BNI sebagaian besar hanya di BNI pusat (BNI Kantor Besar) dan di BNI Kantor Wilayah sehingga tidak menjangkau sampai ke daerah, bank 
pesaing mampu menawarkan bunga dan hadiah yang lebih menarik. Kendala lainnya bagi bank adalah belum diketahuinya secara persis variabel mana dari penerapan Bauran Pemasaran yang sudah berjalan efektif dan variabel mana yang kurang efektif untuk dapat dilakukan perbaikan.

Berdasarkan permasalahan diatas menurut penulis perlu dilakukan penelitian mengenai efektivitas penerapan Bauran Pemasaran di BNI KCP Martapura. Adapun judul tesis pada penelitian ini adalah "Pengaruh Bauran Pemasaran Terhadap Keputusan Menjadi Nasabah PT. Bank Negara Indonesia (persero) Tbk Kantor Cabang Pembantu Martapura".

\section{Perumusan Masalah}

Dari identifikasi masalah di atas penulis melakukan beberapa perumusan masalah diantaranya adalah sebagai berikut:

1. Bagaimanakah pengaruh produk terhadap keputusan menjadi nasabah BNI KCP Martapura?

2. Bagaimanakah pengaruh harga terhadap terhadap keputusan menjadi nasabah BNI KCP Martapura?

3. Bagaimanakah pengaruh promosi terhadap terhadap keputusan menjadi nasabah BNI KCP Martapura?

4. Bagaimanakah pengaruh lokasi bank dan ATM terhadap keputusan menjadi nasabah BNI KCP Martapura?

5. Bagaimanakah pengaruh petugas layanan terhadap keputusan menjadi nasabah BNI KCP Martapura?

6. Bagaimanakah pengaruh sarana fisik bank terhadap terhadap keputusan menjadi nasabah BNI KCP Martapura?

7. Bagaimanakah pengaruh proses jasa dan transaksi bank terhadap terhadap keputusan menjadi nasabah BNI KCP Martapura?

8. Bagaimanakah pengaruh produk, harga, promosi, lokasi, petugas layanan, sarana fisik dan proses suatu bank secara bersama-sama (simultan) terhadap keputusan menjadi nasabah BNI KCP Martapura? 
122 Rozi Sonjaya, Luis Marnisah, Fakhry Zamzam, Pengaruh Bauran Pemasaran....

\section{Tinjauan Pustaka}

\subsubsection{Bauran Pemasaran}

Bauran pemasaran merupakan seperangkat alat pemasaran yang digunakan perusahaan untuk terus menerus mencapai tujuan pemasaran di pasar sasaran (Kotler, 2010). Bauran pemasaran jasa merupakan alat bagi marketer yang terdiri dari beberapa elemen suatu program pemasaran yang perlu dipertimbangkan agar implementasi strategi pemasaran dan positioning yang telah ditetapkan dapat berjalan sukses (Kotler, 2010).

\subsubsection{Produk}

Menurut Tjiptono (2014) produk merupakan segala sesuatu yang dapat ditawarkan produsen untuk diperhatikan, diminta, dicari, dibeli, digunakan atau dikonsumsi pasar yang bersangkutan. Menurut Assauri (2010) produk adalah segala sesuatu yang dapat ditawarkan kepada pasar untuk mendapat perhatian, dimiliki, digunakan atau dikonsumsi yang meliputi barang secara fisik, jasa, kepribadian, tempat, organisasi dan gagasan atau buah pikiran.

\subsubsection{Harga}

Harga (price) adalah jumlah semua nilai yang diberikan oleh Konsumen untuk mendapatkan keuntungan dari memiliki atau menggunakan suatu produk atau jasa (Kolter, 2008). Menurut Daryanto (2011) harga adalah jumlah uang yang ditagih untuk suatu produk atau sejumlah nilai yang dipertukarkan konsumen untuk manfaat memiliki atau menggunakan produk.

\subsubsection{Promosi}

Lupiyoadi (2013), promosi adalah salah satu variabel dalam bauran pemasaran yang sangat penting dilaksanakan oleh perusahaan dalam memasarkan produk barang atau jasa. Menurut Kotler dan Keller (2010) promosi adalah berbagai cara untuk menginformasikan keunggulan produk dan membujuk konsumen untuk membeli suatu produk tersebut.

\subsubsection{Lokasi}

Lokasi (place) adalah tempat dimana suatu jenis usaha atau bidang usaha akan dilaksanakan (Lupiyoadi, 2013). Lokasi memegang peranan penting dalam keberhasilan 
suatu usaha. Pemilihan lokasi usaha memerlukan analisa dan pertimbangan yang cermat, lokasi yang strategis dan mudah dijangkau akan lebih menarik minat pelanggan.

\subsubsection{Orang (Petugas Bank)}

Orang (people) adalah semua pelaku yang memainkan peranan dalam penyajian jasa sehingga dapat memperngaruhi persepsi pembeli (Hurriyati, 2010). Pada perusahaan perbankan, orang adalah karyawan atau petugas bank yang memberikan layanan dan memasarkan produk kepada nasabah seperti petugas Customer Service, Teller, petugas pemasaran dan karyawan yang terlibat secara langsung maupun tidak langsung dalam proses layanan itu sendiri.

\subsubsection{Sarana Fisik (Physical Evidence)}

Sarana fisik (Physical Evidence) adalah suatu hal yang secara nyata turut mempengaruhi keputusan konsumen untuk menggunakan dan membeli produk jasa yang ditawarkan (Lovelock, 2007). Sarana fisik berupa lingkungan fisik suatu bangunan atau kantor tempat dimana usaha dilakukan, seperti bangunan fisik, perlengkapan dan peralatan, selain itu suasana kantor atau bangunan yang menunjang seperti suara, tata ruang, visual, aroma, dan lain-lain.

\subsubsection{Proses}

Proses adalah semua prosedur actual, mekanisme, dan aliran aktivitas yang digunakan untuk menyampaikan jasa (Hurriyati, 2010). Proses pada jasa perbankan berupa semua tahapan dan langka-langkah yang dilakukan petugas Bank dalam memberikan layanan dan memberikan produk yang dibutuhkan nasabah, seperti proses pembukaan rekening, proses pencetakan atau penggantian Buku Tabungan, proses penggantian kartu debit, proses pengiriman uang dan proses transaksi perbankan lainnya.

\subsubsection{Keputusan}

Keputusan merupakan proses pendekatan terhadap penyelesaian suatu masalah yang terdiri dari pengenalan masalah, mencari informasi, beberapa penelitian alternatif, membuat keputusan membeli dan prilaku setelah membeli yang dilalui konsumen (Kotler dan Keller, 2010). Keputusan pembelian pelanggan secara penuh merupakan suatu proses yang berasal dari semua pengalaman mereka dalam pembelajaran, memilih, menggunakan dan bahkan menyingkirkan suatu produk (Kotler dan Keller, 
2010). Menurut Effendy (2003) keputusan adalah fase di mana calon pembeli sudah merasa yakin akan keputusannya, apakah ia akhirnya akan bertindak menolak atau menerima produk yang ditawarkan.

\subsection{Penelitian Sebelumnya}

Sebagai referensi dan acuan dalam penelitian ini, penulis telah mengidentifikasi dan mempelajari beberapa penelitian sebelumnya yang memiliki beberapa kesamaan masalah penelitian, sebagaimana pada tabel dibawah ini.

Tabel 2.1.

Penelitian Sebelumnya

\begin{tabular}{|c|c|c|c|c|c|}
\hline No. & $\begin{array}{l}\text { Nama } \\
\text { Peneliti }\end{array}$ & Judul & Variabel & Metode & Hasil \\
\hline 1 & $\begin{array}{l}\text { Fajri, Arifin, } \\
\text { Wilopo } \\
(2013)\end{array}$ & $\begin{array}{lr}\text { Pengaruh } & \text { Bauran } \\
\text { Pemasaran } & \text { Jasa } \\
\text { Terhadap Keputusan } \\
\text { Menabung } & \text { (survey } \\
\text { pada } & \text { Bank } \\
\text { Muamalat } & \text { Cabang } \\
\text { Malang) } & \end{array}$ & $\begin{array}{l}\text { Variabel } \\
\text { Independen } \\
\text { : Bauran } \\
\text { Pemasaran } \\
\text { Jasa } \\
\text { Variabel } \\
\text { Dependen: } \\
\text { Keputusan } \\
\text { Menabung }\end{array}$ & $\begin{array}{l}\text { Metode } \\
\text { Penelitian } \\
\text { explanatory } \\
\text { survey. } \\
\text { Analisa } \\
\text { Deskriptif } \\
\text { Kuantitatif. }\end{array}$ & $\begin{array}{l}\text { Terdapat } \\
\text { pengaruh } \\
\text { positif dan } \\
\text { signifikan } \\
\text { secara } \\
\text { simultan dan } \\
\text { Parsial antara } \\
\text { Produk, } \\
\text { Harga,Promos } \\
\text { i, Proses, } \\
\text { Orang, Bukti } \\
\text { Fisik dan } \\
\text { Lokasi } \\
\text { terhadap } \\
\text { Keputusan } \\
\text { Menabung }\end{array}$ \\
\hline 2 & $\begin{array}{l}\text { Kondoy, } \\
\text { Tewal, } \\
\text { Worang } \\
(2016)\end{array}$ & $\begin{array}{l}\text { Bauran Pemasaran } \\
\text { dan Pengaruhnya } \\
\text { Terhadap Keputusan } \\
\text { menjadi Nasabah di } \\
\text { BPR Prisma Dana } \\
\text { Manado }\end{array}$ & $\begin{array}{l}\text { Variabel } \\
\text { Independen } \\
\text { : Bauran } \\
\text { Pemasaran } \\
\text { Variabel } \\
\text { Dependen : } \\
\text { Keputusan } \\
\text { Menjadi } \\
\text { Nasabah }\end{array}$ & $\begin{array}{l}\text { Metode } \\
\text { Penelitian } \\
\text { explanatory } \\
\text { survey. } \\
\text { Analisa } \\
\text { Deskriptif } \\
\text { Kuantitatif. }\end{array}$ & $\begin{array}{l}\text { Terdapat } \\
\text { pengaruh } \\
\text { positif dan } \\
\text { signifikan } \\
\text { secara } \\
\text { simultan dan } \\
\text { parsial antara } \\
\text { Produk, } \\
\text { Harga,Tempat } \\
\text { dan Promosi } \\
\text { terhadap } \\
\text { Keputusan } \\
\text { Menjadi } \\
\text { Nasabah }\end{array}$ \\
\hline
\end{tabular}


Ekonomica Sharia: Jurnal Pemikiran dan Pengembangan Ekonomi Syariah Volume 6 Nomor 2 Edisi Februari 2021 125

\begin{tabular}{|c|c|c|c|c|c|}
\hline 3 & $\begin{array}{l}\text { Putra } \\
(2015)\end{array}$ & $\begin{array}{lr}\text { Pengaruh } & \text { Bauran } \\
\text { Pemasaran } & \text { Jasa } \\
\text { Terhadap } & \\
\text { Keputusan } & \text { Memilih } \\
\text { Kredit Konsumtif } \\
\text { pada Bank Jambi } \\
\text { Kota Sungai Penuh }\end{array}$ & $\begin{array}{l}\text { Variabel } \\
\text { Independen } \\
\text { : Bauran } \\
\text { Pemasaran } \\
\text { Jasa } \\
\text { Variabel } \\
\text { Dependen: } \\
\text { Keputusan } \\
\text { Memilih } \\
\text { Kredit } \\
\text { Konsumtif }\end{array}$ & $\begin{array}{l}\text { Metode } \\
\text { Penelitian } \\
\text { explanatory } \\
\text { survey. } \\
\text { Analisa } \\
\text { Deskriptif } \\
\text { Kuantitatif. }\end{array}$ & $\begin{array}{l}\text { Terdapat } \\
\text { Pengaruh } \\
\text { Signifikan } \\
\text { Secara Parsial } \\
\text { antara } \\
\text { Promosi, } \\
\text { Lokasi,Personi } \\
\text { 1, Proses dan } \\
\text { Bukti Fisik } \\
\text { terhadap } \\
\text { Keputusan } \\
\text { Memilih } \\
\text { Kredit } \\
\text { Konsumtif. }\end{array}$ \\
\hline
\end{tabular}

\subsection{Kerangka Pemikiran Teoritis}

Kerangka pikir merupakan penjelasan secara sistematis tentang hubungan antar variabel penelitian yang dituangkan, yang berfungsi untuk mempermudah proses pengumpulan, pengolahan data, mengetahui macam dan jumlah variabel, serta hubungan antar variabel tersebut. Berikut adalah Gambar 2.1 berupa kerangka pikir yang dibuat dan akan digunakan dalam melakukan penelitian. 
126 Rozi Sonjaya, Luis Marnisah, Fakhry Zamzam, Pengaruh Bauran Pemasaran....

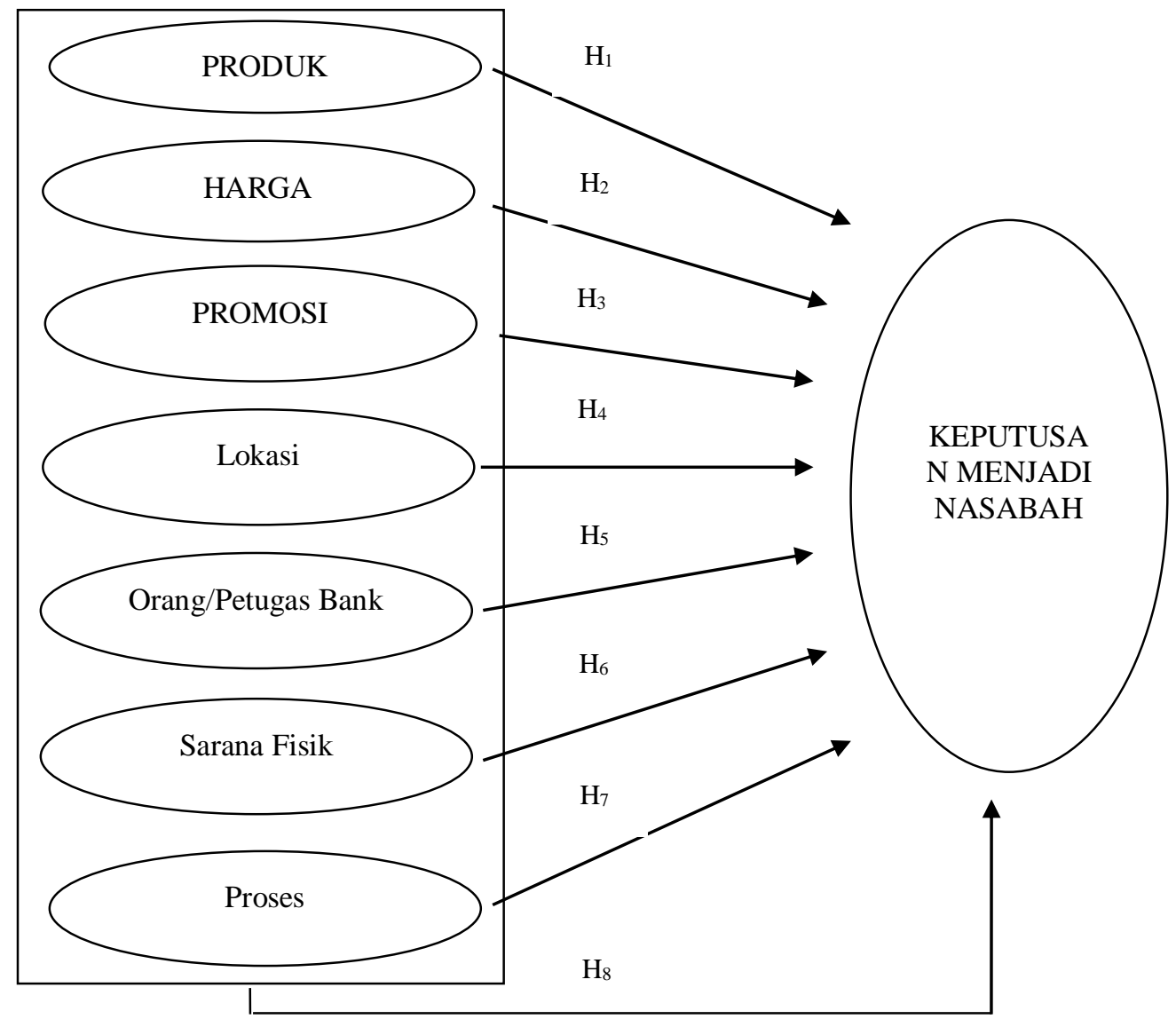

Gambar 2.1.

Kerangka Pikir Penelitian

\section{Metodologi Penelitian}

\subsection{Metode Penelitian}

Penelitian ini menggunakan pendekatan kuantitatif dan kualitatif dengan metode survei. Menurut Sugiyono (2014) pengumpulan data pada penelitian survey dilakukan dengan menggunakan instrumen atau wawancara untuk mendapatkan tanggapan dari responden. Penelitian ini termasuk sebagai penelitian asosiatif. Penelitian asosiatif adalah penelitian yang menganalisis hubungan atau pengaruh variabel bebas (X) terhadap variabel terikat (Y). Penelitian ini menganalisis hubungan atau pengaruh sebab-akibat, antara variabel bebas produk $\left(\mathrm{X}_{1}\right)$, harga $\left(\mathrm{X}_{2}\right)$, promosi $\left(\mathrm{X}_{3}\right)$, lokasi $\left(\mathrm{X}_{4}\right)$, orang $\left(\mathrm{X}_{5}\right)$, sarana fisik $\left(\mathrm{X}_{6}\right)$ dan proses $\left(\mathrm{X}_{7}\right)$ terhadap variabel terikat $(\mathrm{Y})$ keputusan menjadi nasabah. 


\subsection{Populasi dan Sampel}

Populasi dalam penelitian ini adalah semua nasabah yang membuka rekening simpanan di BNI Kantor Cabang Pembantu Martapura pada bulan April tahun 2020 yaitu sebanyak 138 nasabah. Pada penelitian ini seluruh anggota populasi akan dijadikan sebagai sampel, yaitu sebanyak 138 responden.

\subsection{Rencana Analisis Data}

\subsubsection{Pengujian Instrumen Penelitian}

\subsubsection{Uji Validitas}

Uji validitas digunakan untuk mengukur sah atau valid tidaknya suatu kuesioner. Pengujian ini menggunakan taraf signifikansi 5\%. Adapun kriteria penilaian uji validitas, adalah:

1 Apabila $\mathrm{r}$ hitung $>\mathrm{r}$ tabel (pada taraf signifikansi 5\%), maka dapat dikatakan item kuesioner tersebut valid.

2. Apabila $\mathrm{r}$ hitung $<\mathrm{r}$ tabel (pada taraf signifikansi 5\%), maka dapat dikatakan item kuesioner tersebut tidak valid.

\subsubsection{Uji Reliabilitas}

Uji reliabilitas sebenarnya adalah alat untuk mengukur suatu kuesioner yang merupakan indikator dari variabel atau konstruk. Suatu kuesioner dikatakan reliable atau handal jika jawaban sesorang terhadap pernyataan adalah konsisten atau stabil dari waktu ke waktu (Ghozali, 2016). Uji reliabilitas dapat dilakukan secara bersama-sama terhadap seluruh butir pertanyaan. Jika $\alpha>0,60$ maka reliabel (Sujarweni, 2015).

\subsubsection{Uji Asumsi Klasik}

\subsubsection{Uji Normalitas}

Uji normalitas bertujuan untuk menguji apakah dalam model regresi, variabel pengganggu atau residual memiliki distribusi normal (Ghozali, 2016). Pengujian normalitas dilakukan dengan melihat nilai 2-tailed significant. Jika data memiliki tingkat signifikansi lebih besar dari 0,05 atau 5\% maka dapat disimpulkan bahwa H0 diterima, sehingga data dikatakan berdistribusi normal (Ghozali, 2016). 


\subsubsection{Uji Multikolinearitas}

Uji multikolinearitas bertujuan untuk menguji apakah modelregresi ditemukan adanya korelasi antar variabel bebas (independen). Variabel ortogonal adalah variabel independen yang nilai korelasi antar sesama variabel independen sama dengan nol. Identifikasi secara statistik untuk menunjukkan ada tidaknya gejala multikolinieritas dapat dilakukan dengan melihat nilai VIF (Variance Inflation Factor).

\subsubsection{Uji Heterokedastisitas}

Uji heteroskedastisitas bertujuan menguji apakah dalam model regresi terjadi ketidaksamaan varian dari residual satu pengamatan ke pengamatan lain. Deteksi ada tidaknya heteroskedastisitas dapat dilakukan dengan melihat ada tidaknya pola tertentu pada grafik scatterplot antara ZPRED 51 dan SRESID dimana sumbu Y adalah Y yang telah diprediksi dan sumbu $\mathrm{X}$ adalah residual (Y prediksi-Y sesungguhnya).

\subsubsection{Uji Linearitas}

Uji ini digunakan untuk melihat apakah spesifikasi model yang digunakan sudah benar atau tidak (Ghozali, 2016). Kriteria yang diterapkan untuk menyatakan linear adalah nilai $\mathrm{F}$ yang dihitung dengan rumus (Hadi, 2014). Harga bilangan F untuk regresi, Rerata kuadrat garis regresi, Rerata kuadrat garis residu. Jika Sig> 0,05, maka hubungan antara variabel bisa dikatakan linear.

\subsection{Analisis Regresi Linier Berganda}

\subsubsection{Persamaan Regresi}

Metode analisis yang digunakan dalam penelitian ini adalah metode Analisis Regresi Linear Berganda. Analisis ini digunakan dengan melibatkan dua atau lebih variabel bebas antara variabel dependen (Y) dan variabel independen, cara ini digunakan untuk mengetahui kuatnya hubungan antara beberapa variabel bebas secara serentak terhadap variabel terkait dan dinyatakan dengan rumus sebagai berikut:

$\mathrm{Y}=\mathrm{a}+\beta_{1 \mathrm{X} 1}+\beta_{2 \mathrm{X}_{2}}+\beta_{3 \mathrm{X}_{3}}+\beta_{4 \mathrm{X}_{4}}+\beta_{5} \mathrm{X}_{5}+\beta_{6} \mathrm{X}_{6}+\beta_{7 \mathrm{X} 7}+\mathrm{e}$ 
Keterangan:

$\mathrm{Y}=$ Variabel Dependen

$\mathrm{a}=$ Konstanta

$\beta_{1}, \beta_{2}, \beta_{3}, \beta_{4}, \beta_{5}, \beta_{6}, \beta_{7}=$ Koefisien Regresi

$\mathrm{X}_{1}, \mathrm{X}_{2}, \mathrm{X}_{3}, \mathrm{X}_{4}, \mathrm{X}_{5}, \mathrm{X}_{6}, \mathrm{X}_{7}=$ Variabel Independen

$\mathrm{e}=$ Standard Error

\subsection{Rancangan Pengujian Hipotesis}

\subsubsection{Uji t (Secara Parsial)}

Uji t pada dasarnya menunjukkan seberapa jauh pengaruh satu variabel independen secara individual dalam menerangkan Variabel dependen (Ghozali, 2016). Kriteria pengambilan keputusan adalah sebagai berikut:

Dasar pengambilan keputusan berdasarkan nilai signifikansi hasil dari output SPSS:

a) Jika nilai Sig. < 0,05 maka variabel bebas $(\mathrm{X})$ berpengaruh signifikan terhadap variabel terikat $(\mathrm{Y})$.

b) Jika nilai Sig. > 0,05 maka variabel bebas $(\mathrm{X})$ tidak berpengaruh signifikan terhadap variabel terikat $(\mathrm{Y})$.

\subsubsection{Uji F (Uji Serentak)}

Uji statistik F pada dasarnya menunjukkan apakah semua variabel independen atau bebas yang dimasukkan dalam model mempunyai pengaruh secara bersamasama terhadap variable dependen atau terikat (Ghozali, 2016). Untuk menguji hipotesis ini digunakan statistik F dengan kriteria pengambilan keputusan sebagai berikut:

Dasar pengambilan keputusan berdasarkan nilai signifikansi hasil dari output SPSS :

a) Jika nilai Sig. < 0,05 maka variabel bebas $(\mathrm{X})$ secara simultan berpengaruh signifikan terhadap variabel terikat (Y).

b) Jika nilai Sig. > 0,05 maka variabel bebas (X) secara simultan tidak berpengaruh signifikan terhadap variabel terikat (Y). 
130 Rozi Sonjaya, Luis Marnisah, Fakhry Zamzam, Pengaruh Bauran Pemasaran....

\section{Hasil Dan Pembahasan}

\subsection{Pengujian Instrumen Penelitian}

\subsubsection{Uji Validitas}

Hasil uji validitas pada penelitian ini sebagaimana pada tabel berikut.

Tabel 4.1.

Hasil Uji Validitas

\begin{tabular}{|c|c|c|c|c|}
\hline Variabel & $\begin{array}{c}\text { Kode } \\
\text { Pernyataa } \\
\text { n }\end{array}$ & r-hitung & r-tabel & $\begin{array}{c}\text { Keteranga } \\
\mathbf{n}\end{array}$ \\
\hline \multirow{4}{*}{ Produk $\left(\mathrm{X}_{1}\right)$} & PRD1 & 0,726 & 0,1672 & Valid \\
\hline & PRD2 & 0,749 & 0,1672 & Valid \\
\hline & PRD3 & 0,795 & 0,1672 & Valid \\
\hline & PRD4 & 0,773 & 0,1672 & Valid \\
\hline \multirow{5}{*}{$\operatorname{Harga}\left(\mathrm{X}_{2}\right)$} & HRG1 & 0,765 & 0,1672 & Valid \\
\hline & HRG2 & 0,737 & 0,1672 & Valid \\
\hline & HRG3 & 0,790 & 0,1672 & Valid \\
\hline & HRG4 & 0,793 & 0,1672 & Valid \\
\hline & HRG5 & 0,748 & 0,1672 & Valid \\
\hline \multirow{4}{*}{ Promosi $\left(\mathrm{X}_{3}\right)$} & PRM1 & 0,845 & 0,1672 & Valid \\
\hline & PRM2 & 0,807 & 0,1672 & Valid \\
\hline & PRM3 & 0,803 & 0,1672 & Valid \\
\hline & PRM4 & 0,802 & 0,1672 & Valid \\
\hline \multirow{4}{*}{ Lokasi $\left(\mathrm{X}_{4}\right)$} & LKS1 & 0,782 & 0,1672 & Valid \\
\hline & LKS2 & 0,830 & 0,1672 & Valid \\
\hline & LKS3 & 0,829 & 0,1672 & Valid \\
\hline & LKS4 & 0,669 & 0,1672 & Valid \\
\hline \multirow{5}{*}{ Orang/Petugas Bank $\left(\mathrm{X}_{5}\right)$} & ORG1 & 0,807 & 0,1672 & Valid \\
\hline & ORG2 & 0,848 & 0,1672 & Valid \\
\hline & ORG3 & 0,865 & 0,1672 & Valid \\
\hline & ORG4 & 0,849 & 0,1672 & Valid \\
\hline & ORG5 & 0,806 & 0,1672 & Valid \\
\hline \multirow{4}{*}{ Sarana Fisik $\left(\mathrm{X}_{6}\right)$} & SRF1 & 0,751 & 0,1672 & Valid \\
\hline & SRF2 & 0,841 & 0,1672 & Valid \\
\hline & SRF3 & 0,821 & 0,1672 & Valid \\
\hline & SRF4 & 0,818 & 0,1672 & Valid \\
\hline \multirow{4}{*}{ Proses $\left(\mathrm{X}_{7}\right)$} & PRS1 & 0,833 & 0,1672 & Valid \\
\hline & PRS2 & 0,833 & 0,1672 & Valid \\
\hline & PRS3 & 0,860 & 0,1672 & Valid \\
\hline & PRS4 & 0,862 & 0,1672 & Valid \\
\hline \multirow{3}{*}{$\begin{array}{l}\text { Keputusan Menjadi } \\
\text { Nasabah (Y) }\end{array}$} & KMN1 & 0,832 & 0,1672 & Valid \\
\hline & KMN2 & 0,875 & 0,1672 & Valid \\
\hline & KMN3 & 0,875 & 0,1672 & Valid \\
\hline
\end{tabular}




\begin{tabular}{|l|c|c|c|c|}
\hline & KMN4 & 0,747 & 0,1672 & Valid \\
\hline
\end{tabular}

Sumber: Diolah dari data primer (2020)

Tabel 4.1. memberikan informasi bahwa seluruh item pernyataan mempunyai $r$ hitung $>\mathrm{r}$ tabel yaitu pada taraf signifikan $5 \%$ dan $\mathrm{n}=138(\mathrm{n}=138-2)$, diperoleh $\mathrm{r}$ tabel $=$ 0,1672, sehingga seluruh item variabel penelitian dinyatakan valid.

\subsection{Uji Reliabilitas}

Uji reliabilitas dapat dilakukan secara bersama-sama terhadap seluruh butir pertanyaan. Jika $\alpha>0,60$ maka reliabel (Sujarweni, 2015).

Hasil uji reliabilitas pada penelitian ini sebagai berikut:

Tabel 4.2.

Hasil Uji Reliabilitas

\begin{tabular}{|c|c|c|}
\hline Variabel & Cronbach's Alpha & Keterangan \\
\hline Produk $\left(\mathrm{X}_{1}\right)$ & 0,756 & Reliabel \\
\hline Harga $\left(\mathrm{X}_{2}\right)$ & 0,819 & Reliabel \\
\hline Promosi $\left(\mathrm{X}_{3}\right)$ & 0,830 & Reliabel \\
\hline Lokasi $\left(\mathrm{X}_{4}\right)$ & 0,782 & Reliabel \\
\hline Orang/Petugas Bank $\left(\mathrm{X}_{5}\right)$ & 0,890 & Reliabel \\
\hline Sarana Fisik $\left(\mathrm{X}_{6}\right)$ & 0,811 & Reliabel \\
\hline Proses $\left(\mathrm{X}_{7}\right)$ & 0,867 & Reliabel \\
\hline $\begin{array}{c}\text { Keputusan Menjadi Nasabah } \\
(\mathrm{Y})\end{array}$ & 0,853 & Reliabel \\
\hline
\end{tabular}

Sumber: Diolah dari data primer (2020)

Tabel 4.2. memberikan informasi bahwa seluruh variabel memiliki nilai Cronbach's Alpha > 0,60, sehingga seluruh variabel penelitian dinyatakan Reliabel.

\subsection{Hasil Pengujian Asumsi Klasik}

\subsubsection{Hasil Pengujian Normalitas}

Hasil pengujian normalitas Kolmogorov -Smirnov dengan menggunakan program SPSS 22 diperoleh hasil nilai 2-tailed significant sebesar 0,200> dari 0,05 sehingga data dikatakan berdistribusi normal. 
132 | Rozi Sonjaya, Luis Marnisah, Fakhry Zamzam, Pengaruh Bauran Pemasaran....

\subsubsection{Hasil Pengujian Multikolinearitas}

Multikolinieritas dapat dilihat dari nilai tolerance dan Variance Inflation Factor (VIF). Hasil penelitian menunjukkan bahwa nilai VIF semua variabel bebas lebih kecil dari 10 dan nilai tolerance semua variabel bebas lebih dari 0.10 . Hal ini menunjukkan tidak terjadi gejala multikolinieritas.

\subsubsection{Hasil Pengujian Heterokedastisitas}

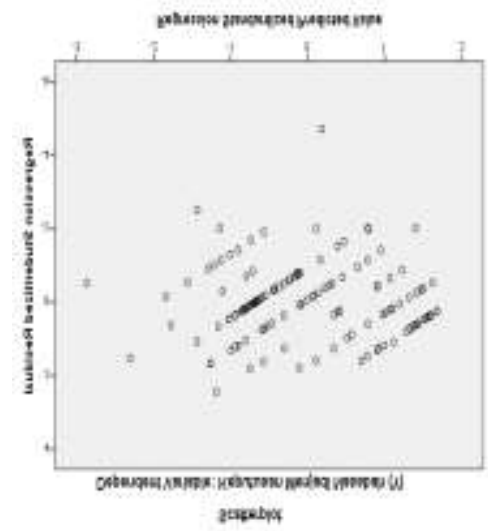

Hasil pengujian heterokedastisitas pada gambar 4.2 di atas menunjukkan, titik-titik yang menyebar baik di atas maupun di bawah angka 0 (nol) pada sumbu Y, hal ini menunjukkan tidak terjadi penyimpangan asumsi klasik heteroskedastisitas pada model regresi yang dibuat.

\subsubsection{Hasil Pengujian Linearitas}

Uji ini digunakan untuk melihat apakah spesifikasi model yang digunakan sudah benar atau tidak (Ghozali, 2016). Informasi dari tabel analisismenyatakan bahwa hasil pengujian linearitas semua variabel telah > dari 0,05, maka hubungan variabel dependen dan variabel independen telah seluruhnya telah linear. Sehingga hasil uji linearitas bahwa variabel penelitian telah memenuhi kriteria linearitas.

\subsection{Hasil Analisis Regresi Linier Berganda}

Analisis ini digunakan untuk mengetahui pengaruh baik secara parsial maupun secara simultan dari variable independen $(\mathrm{X})$ dengan variable dependen $(\mathrm{Y})$. Analisis regresi linier berganda digunakan untuk melakukan prediksi, bagaimana perubahan nilai 
variabel dependen bila nilai variabel independen dinaikkan atau diturunkan nilainya (Sugiyono, 2014). Hasil analisis regresi linier berganda dapat dilihat pada gambar dibawah ini.

Tabel 4.3.

Hasil Uji Regresi
Coefficients $^{\mathrm{a}}$

\begin{tabular}{|c|c|c|c|c|c|}
\hline \multirow[b]{2}{*}{ Model } & \multicolumn{2}{|c|}{ Unstandardized Coefficients } & \multirow{2}{*}{$\frac{\text { Standardized Coefficients }}{\text { Beta }}$} & \multirow[b]{2}{*}{$\mathrm{t}$} & \multirow[b]{2}{*}{ Sig. } \\
\hline & $\mathrm{B}$ & Std. Error & & & \\
\hline 1 (Constant) & -.912 & 1.242 & & -.734 & 464 \\
\hline Produk (X1) & .136 & .071 & .12 & 1.901 & .060 \\
\hline Harga (X2) & -.034 & .068 & -.04 & -.507 & 613 \\
\hline Promosi (X3) & .148 & .081 & .14 & 1.826 & .070 \\
\hline Lokasi (X4) & .324 & .085 & .25 & 3.790 & .000 \\
\hline Orang / Petugas Bank (X5) & 175 & .063 & .23 & 2.771 & .006 \\
\hline Sarana Fisik (X6) & .093 & .073 & $.0 s$ & 1.276 & 204 \\
\hline Proses (X7) & .154 & .093 & .15 & 1.650 & .101 \\
\hline
\end{tabular}

a. Dependent Variable: Keputusan Menjadi Nasabah (Y)

Sumber: Diolah dari data primer (2020)

Dari table 4.3. dapat dibuat persamaan linear berganda yang digunakan adalah sebagai berikut:

$\mathrm{Y}=-0,912+0,136 \mathrm{PRD}+-0,034 \mathrm{HRG}+0,148 \mathrm{PRM}+0,324 \mathrm{LKS}+0,175 \mathrm{ORG}+$ $0,093 \mathrm{SRF}+0,154 \mathrm{PRS}$

\subsection{Hasil Pengujian Hipotesis}

\subsubsection{Hasil Uji t}

Uji t pada dasarnya menunjukkan seberapa jauh pengaruh satu variabel independen secara individual dalam menerangkan Variabel dependen (Ghozali, 2016). Hasilnya dapat dilihat pada tabel di bawah ini:

Tabel 4.4.

Hasil Uji t

\begin{tabular}{|l|l|l|l|}
\hline Variabel & t-hitung & sig & keputusan \\
\hline produk & 1,901 & 0,060 & Tidak berpengaruh \\
\hline Harga $(\mathrm{X} 2)$ & $-0,507$ & 0,613 & Tidak berpengaruh \\
\hline Promosi $(\mathrm{X} 3)$ & 1,826 & 0,070 & berpengaruh \\
\hline Lokasi $(\mathrm{X} 4)$ & 3,790 & 0,000 & berpengaruh \\
\hline Orang/Petugas Bank $(\mathrm{X} 5)$ & 2,771 & 0,006 & berpengaruh \\
\hline Sarana Fisik $\left(\mathrm{X}_{6}\right)$ & 1,276 & 0,204 & Tidak berpengaruh \\
\hline Proses $\left(\mathrm{X}_{7}\right)$ & 1,650 & 0,101 & Tidak berpengaruh \\
\hline
\end{tabular}




\section{4 | Rozi Sonjaya, Luis Marnisah, Fakhry Zamzam, Pengaruh Bauran Pemasaran....}

Berdasarkan tabel 4.22 diketahui $t$ hitung sebesar 1,901 < dengan $t$ tabel 1.978 dan tingkat signifikansi 0,060 >0,05, maka hipotesis $\mathrm{H}_{0}$ diterima dan $\mathrm{H}_{1}$ ditolak sehingga hasil pengujian hipotesis menunjukkan bahwa tidak terdapat pengaruh signifikan produk terhadap keputusan menjadi nasabah. $\mathrm{H}_{2}$ ditolak maka hasil pengujian hipotesis menunjukkan bahwa tidak terdapat pengaruh signifikan harga terhadap keputusan menjadi nasabah. $\mathrm{H}_{3}$ ditolak maka hasil pengujian hipotesis menunjukkan bahwa tidak terdapat pengaruh signifikan promosi terhadap keputusan menjadi nasabah.

Berdasarkan tabel 4.25 diketahui t hitung sebesar 3,790 > dengan t tabel 1.978 dan tingkat signifikansi 0,000 <0,05, maka hipotesis H0 ditolak dan H4 diterima maka hasil pengujian hipotesis menunjukkan bahwa terdapat pengaruh positif dan signifikan lokasi terhadap keputusan menjadi nasabah. H5 diterima maka hasil pengujian hipotesis menunjukkan bahwa terdapat pengaruh positif dan signifikan Orang/Petugas Bank terhadap keputusan menjadi nasabah

Berdasarkan tabel 4.27 diketahui t hitung sebesar 1,276 < dengan t tabel 1.978 dan tingkat signifikansi 0,204 > 0,05, maka hipotesis H0 diterima dan H6 ditolak maka hasil pengujian hipotesis menunjukkan bahwa tidak terdapat pengaruh signifikan Sarana Fisik terhadap keputusan menjadi nasabah. H7 ditolak maka hasil pengujian hipotesis menunjukkan bahwa tidak terdapat pengaruh signifikan Proses terhadap keputusan menjadi nasabah.

\subsubsection{Hipotesis Pengaruh Produk, Harga, Promosi, Lokasi, Orang / Petugas}

\section{Bank, Sarana Fisik dan Proses Terhadap Keputusan Menjadi Nasabah}

Hasil uji F dengan menggunakan program SPSS dapat dilihat pada tabel dibawah ini.

Tabel 4.5.

Hasil Uji F

\begin{tabular}{|l|c|c|}
\hline \multicolumn{1}{|c|}{ Variabel } & Nilai F hitung & Sig \\
\hline $\begin{array}{l}\text { Produk, Harga, Promosi, } \\
\text { Lokasi, Orang/Petugas Bank, } \\
\text { Sarana Fisik, Proses }\end{array}$ & 35,055 & 0,000 \\
\hline
\end{tabular}

Sumber: Diolah dari data primer (2020) 
Berdasarkan tabel 4.29 diketahui $F$ hitung sebesar 35,055 > dengan $F$ tabel 2,08 dan tingkat signifikansi $0,000<0,05$, maka hipotesis $\mathrm{H}_{0}$ ditolak dan $\mathrm{H}_{8}$ diterima maka hasil pengujian hipotesis menunjukkan bahwa terdapat pengaruh positif dan signifikan produk, harga, promosi, lokasi, orang / petugas bank, sarana fisik dan proses secara simultan terhadap keputusan menjadi nasabah.

\section{Simpulan dan Implikasi Manajerial}

\section{Kesimpulan}

Berdasarkan hasil pengujian hipotesis, analisis dan pembahasan yang telah dilakukan, maka dapat diambil kesimpulan sebagai berikut:

1. Variabel produk tidak berpengaruh terhadap keputusan menjadi nasabah.

2. Variabel harga tidak berpengaruh terhadap keputusan menjadi nasabah.

3. Variabel promosi tidak berpengaruh terhadap keputusan menjadi nasabah.

4. Variabel lokasi berpengaruh terhadap keputusan menjadi nasabah.

5. Variabel orang / petugas bank berpengaruh terhadap keputusan menjadi nasabah.

6. Variabel sarana fisik tidak berpengaruh terhadap keputusan menjadi nasabah.

7. Variabel proses tidak berpengaruh terhadap keputusan menjadi nasabah.

8. Variabel Lokasi paling berpengaruh signifikan terhadap keputusan menjadi nasabah.

9. Variabel produk, harga, promosi, lokasi, orang / petugas bank, sarana fisik dan proses secara bersama-sama berpengaruh positif dan signifikan terhadap keputusan menjadi nasabah.

\section{Implikasi Manajerial}

Strategi untuk meningkatkan minat masyarakat menjadi nasabah BNI KCP Martapura dapat dilakukan dengan mempertahankan lokasi strategis yang telah dimiliki, dimana akses menuju BNI KCP Martapura mudah dijangkau oleh masyarakat sehingga dapat meningkatkan minat masyarakat untuk menjadi nasabah BNI KCP Martapura. Strategi lainnya dengan tetap memperhatikan dan mempertahankan skill dan sikap petugas layanan yang telah baik seperti keramahan customer service, teller dan satpam sehingga dapat membantu BNI KCP Martapura dalam meningkatkan jumlah nasabah. 
136 Rozi Sonjaya, Luis Marnisah, Fakhry Zamzam, Pengaruh Bauran Pemasaran....

\section{DAFTAR PUSTAKA}

Aravik, H.; A. I. H. (2021). Etika Perbankan Syariah: Teori dan Implementasi. Deepublish..

Aravik, H., Sulastyawati, D., \& Yunus, N. R. (2020). Leadership Concept At Sharia Bank; A Theoretical Study. Islamic Banking: Jurnal Pemikiran Dan Pengembangan Perbankan Syariah, 5(2), 21-32.

Assauri, Sofjan. 2010. Manajemen Pemasaran: Konsep, Dasar dan Strategi. Jakarta: PT. Raja Grafindo Persada.

Badan Pusat Statistik. Bank dan Kantor Bank, 2010-2017. https://www.bps.go.id/staticable/2015/09/28/1856/bank-dan-kantor-bank-20102017.html. diakses tanggal 24 Januari 2019.

Bank Negara Indonesia. Visi \& Misi. https://www.bni.co.id/idid/perusahaan/tentang bni/visimisi. diakses tanggal 24 Januari 2019.

Bank Negara Indonesia. BNI Deposito. https://www.bni.co.id/id $\mathrm{id} /$ personal/simpanan/bnideposito. diakses tanggal 01 Juni 2020

Daryanto. 2011. Manajemen Pemasaran. Bandung: PT Sarana Tutorial Nurani Sejahtera.

Fajri, Detha Alfrian, Zainul Arifin dan Wilopo. 2013. Pengaruh Bauran Pemasaran Jasa Terhadap Keputusan Menabung (Survei Pada Nasabah Bank Muamalat Cabang Malang). Jurnal Administrasi Bisnis Vol.6 No.2.

Ghozali, Imam. 2016. Aplikasi Analisis Multivariete Dengan Program IBM SPSS. Semarang: Badan Penerbit Universitas Diponegoro.

Hadi, Sutrisno. 2014. Statistika. Yogyakarta: Pustaka Pelajar.

Hurriyati, Ratih. 2010. Bauran Pemasaran dan Loyalitas Konsumen. Bandung: Alfabeta.

Kondoy, Beatric MJ, Benhard Tewal, Frederik Worang. 2016. Bauran Pemasaran dan Pengaruhnya Terhadap Keputusan Menjadi Nasabah di BPR Prisma Dana Manado. Jurnal EMBA Vol.4 No.4.

Kotler, Philip dan Kevin Lane Keller. 2010. Manajemen Pemasaran. Jakarta: Erlangga.

Kotler, Philip dan Gary Armstrong. 2008. Prinsip-Prinsip Pemasaran. Jakarta: Erlangga.

Lupiyoadi, Rambat. 2013. Manajemen Pemasaran Jasa Berbasis Kompetensi. Jakarta: Salemba Empat.

Lovelock, Christopher dan Lauren K. Wright, 2007, Manajemen Pemasaran Jasa. Jakarta: PT. Indeks. 
Ekonomica Sharia: Jurnal Pemikiran dan Pengembangan Ekonomi Syariah Volume 6 Nomor 2 Edisi Februari 2021 | 137

Putra, Adi Kurnia. 2015. Pengaruh Bauran Pemasaran Jasa Terhadap Keputusan Memilih Kredit Konsumtif pada Bank Jambi Kota Sungai Penuh. Tesis Universitas Bung Hatta.

Sugiyono. 2017. Statistika Untuk Penelitian. Bandung: Alfabeta.

Sugiyono. 2014. Metode Penelitian Kuantitatif Kualitatif dan R\&D. Bandung: Alfabeta

Sujarweni, Wiratna. 2015. Statistika Untuk Bisnis dan Ekonomi. Yogyakarta: Pustaka Baru Press.

Tjiptono, Fandy. 2014. Strategi Pemasaran. Yogyakarta: Andi Offset.

Zamzam, F. (2018). Aplikasi Metodologi Penelitian. Yogyakarta: CV. Budi Utama. 